\title{
Historical Sources as a Teaching Tool
}

\author{
Inna Pivkina \\ New Mexico State University \\ Las Cruces, NM 88003 \\ 1-575-646-6237 \\ ipivkina@cs.nmsu.edu
}

\author{
Desh Ranjan \\ New Mexico State University \\ Las Cruces, NM 88003 \\ 1-575-646-4600 \\ dranjan@cs.nmsu.edu
}

\author{
Jerry Lodder \\ New Mexico State University \\ Las Cruces, NM 88003 \\ 1-575-646-2835 \\ jlodder@nmsu.edu
}

\begin{abstract}
SUMMARY
The session will introduce participants to curricular modules (projects) based entirely on primary historical source material, developed by an interdisciplinary team of seven computer science and mathematical sciences faculty at New Mexico State University and Colorado State University - Pueblo. More than twenty projects have been developed and are available on the Internet at: http://www.cs.nmsu.edu/historical-projects/ . The projects are intended for courses in discrete mathematics, algorithm design, automata, graph theory, and logic.
\end{abstract}

\section{Categories and Subject Descriptors}

K.3.2 [Computers and Education]: Computer and Information Science Education; G.2.0 [Discrete Mathematics]: General.

\section{General Terms}

Algorithms, Theory.

\section{Keywords}

Pedagogy, historical sources, algorithms, discrete mathematics, projects, assignments.

\section{OBJECTIVE}

\subsection{Overall Objective}

This session will introduce the participants to curricular modules (projects) which use history as a tool to help students learn computer science and mathematics. Each project is built around primary source materials close to or representing the discovery of a key concept. The audience will learn how to use the projects and have a hands-on experience with the projects. After the session participants will have access to the materials and will be able to use the projects in their courses.

\subsection{Why historical sources?}

Computer science students often lack mathematical background and find courses such as discrete mathematics and algorithms very hard. Using original historical sources provides context and direction to subject matter, honing the students' verbal and deductive skills through reading the work of some of the greatest minds in history.

Teaching something very distilled or polished does not help the students in seeing how they can develop ideas themselves. Some

Copyright is held by the author/owner(s)

SIGCSE'09, March 3-7, 2009, Chattanooga, Tennessee, USA.

ACM 978-1-60558-183-5/09/03. original sources may show step by step research processes of the author. Reading the source and reproducing experiments which the author did gives students the experience of walking with the researcher, making them familiar with the research process. Often in the words of original author there will be insights into the process of the discovery presented by the discoverer him- or herself. It also gives students a realization that a human being discovered this and they can make discoveries, too.

The styles in which original sources are written often require students to interpret and explain in their own words thereby getting a deeper understanding of the content. Teaching with primary sources provides instructors with a lot of opportunities to create a variety of tasks for students. Variety in tasks allows students with different learning styles to flourish.

Original sources level the playing field. All students are equally unfamiliar with original sources. Weaker students may be more willing to jump in on something where they know other students do not have any advantage. Students may feel more empowered to question an original source than to question their textbook or instructor. Original sources by their nature invite questions while textbooks do not usually invite questions.

We found out that students who completed a course with projects performed better in subsequent courses. They scored better than the mean GPA in $64 \%$ of the cases for Math and in $62 \%$ of the cases for CS.

\section{OVERVIEW}

\subsection{Outline of the Session}

The session will consist of two parts. In the first part we will present pedagogy, provide brief description of projects that are being developed and tested, give an overview of how the materials can be used in undergraduate courses, discuss student reactions to the projects and observed effects of using the projects in the classroom (15 min). Each of the presenters will talk about one selected project from Section 2.2 in detail (5 min each). In the second part, participants will have the opportunity to work on one of the projects - perform the project tasks that students would do when the project is used in the classroom (35 min). The activities will be facilitated by the presenters, each of which developed and tested projects in their classes. The session will end with a summary discussion (10 min).

Special session format will be the best because it allows combining presentations with hands-on exercises and discussion. 


\subsection{Selected Projects}

\subsubsection{Deduction through the Ages: A History of Truth}

Dr. Lodder will introduce the project "Deduction through the Ages: A History of Truth" intended for introductory courses in discrete mathematics and computer science. The project provides historical and motivational material for the system of logic used today that reduces statements and a calculation of their validity to either "true" or "false." The roots of propositional logic are traced from the work of the ancient Greek philosopher Chrysippus (280--206 BCE) [5], whose verbal description of the rules of inference included five basic syllogisms stated using the words "and," "or," "not," and "if-then." These rules are then cast in terms of their truth values using the elaborate concept-script of Gottlob Frege (1848--1925) [3], in which certain logical equivalences begin to emerge. This is compared with streamlined notation of Bertrand Russell (1872--1970) and Alfred N. Whitehead (1861--1947) [6] along with their own description of the meaning of their symbols for the concepts of "and," "or," "not," and "if-then." Finally the schemata (truth-tables) of Ludwig Wittgenstein (1889--1951) [7] are introduced and used to resolve questions of logical equivalence among Chrysippus' original rules of inference.

\subsubsection{Euclid's Algorithm for the Greatest Common Divisor}

Dr. Ranjan will present the project "Euclid's Algorithm for the Greatest Common Divisor.” The project is based on Proposition 2 of Book VII of Euclid's Elements [1], written around 300 BCE, where he presents his algorithm "to find the greatest common measure of two given numbers not relatively prime" and its important corollary that "if a number measures two numbers, then it also measures their greatest common measure." The project can be used to introduce students to the notion of "computation method" or "algorithm" and to explore concepts like iteration in a basic setting. It allows students to practice their skills in doing proofs, but more importantly, to observe the evolution of what is accepted as a valid proof or a well-described algorithm. The students will easily notice that the method presented by Euclid to compute the greatest common divisor (GCD) of two integers and proof of its correctness that he provided would not be formally accepted as correct today. They will also notice, however, that Euclid is somehow able to convey his ideas behind his method and proof in a way that they can be easily translated into a modern algorithm and proof of its correctness. In this way, it will provide students a sense of connection to the past as well as help them understand that it is possible to develop creative ideas without worrying about formal notation or correctness and that one can use formal notation and proofs to establish the validity of the ideas.

\subsubsection{Discovery of Huffman codes}

Dr. Pivkina will talk about the project "Discovery of Huffman codes” designed for courses in data structures and analysis of algorithms. One of the most well-known codes is Morse code, which was used for transmitting telegraphic information. In Morse code, shorter codewords are used for letters which are more common in English, such as ' $e$ ' and ' $t$ '. This reduces the amount of data needed for transmission which is a goal of data compression. Researchers tried to devise an optimal coding, that is, a coding which would yield the best data compression, or the lowest possible average message length. In 1949, C. Shannon and R. Fano developed a systematic method to assign codewords based on probabilities of blocks. However, their coding did not always produce optimal codes; it only approached the optimal behavior. Fano was a professor at MIT. In 1951 he gave his students a choice of either taking a final exam or writing a term paper on the problem of finding the most efficient code. He did not tell his students that he was working on the problem himself. One of the students, David Huffman, did not want to take the exam and developed an algorithm that produced optimal codes, thus, he outdid his professor. Both Shannon-Fano and Huffman encodings are produced by greedy algorithms. The project uses Fano's and Huffman's papers [2,4] to look into prefix-free codes, binary tree representations of codes, and greedy algorithms.

\section{INTENDED AUDIENCE}

This session is for anyone who is interested in using history as a tool for teaching, or just looking for new ideas for student projects. It will be especially useful for instructors who teach courses in discrete mathematics, algorithm design, automata, graph theory, and logic, because they could use some of the developed projects in their classes.

\section{ACKNOWLEDGMENTS}

The material is based upon work supported by the National Science Foundation under award number 0717752. Any opinions, findings, and conclusions or recommendations expressed in this publication are those of the authors and do not necessarily reflect the views of the National Science Foundation.

\section{REFERENCES}

For further information about the projects based on original historical sources, please refer to the following URL:

http://www.cs.nmsu.edu/historical-projects/

[1] Euclid. The Thirteen Books of Euclid's Elements. T.L.Heath (editor), Dover, New York, 1956, Book VII.

[2] Fano, R.M. 1949. The Transmission of Information. Technical Report No. 65, Research Laboratory of Electronics, M.I.T., Cambridge, Mass.

[3] Frege, G. Grundgesetze der Arithmetik: Begriffschriftlich abgeleitet (photographic reproduction). Georg Olms, Hildesheim, 1962.

[4] Huffman, D. A. A method for the construction of minimumredundancy codes. Proc. of the Institute of Radio Engineers, 40(9):1098-1101, September 1952.

[5] Long, A. A., Sedley, D. N. 1987. The Hellenistic Philosophers, Vol. I, Cambridge University Press, Cambridge, England.

[6] Russell, B., Whitehead, A. N. 1997. Principia Mathematica to *56. Cambridge University Press, Cambridge, England.

[7] Wittgenstein, L. Logisch-Philosophische Adhundlung. Annalen der Naturphilosophie, 14 (1921). 